с. Меловое и участок степи у с. Тараховка имеют исключительное значение для сохранения ландшафтного и биологического разнообразия степного Заволжья. Уникальность данных участков вызвана не только природными условиями, обусловливающими эндемичность флоры и высокий уровень биоразнообразия, но и административнохозяйственным положением, характеризующимся большой удаленностью от областного центра, приграничным положением. В целом весь район Дальнего Саратовского Заволжья выделяется своеобразными природными условиями и особенностями хозяйственного использования, что позволяет рассматривать его как одну из опорных территорий для развития природно-заповедного фонда Саратовской области. Однако для развития степных охраняемых территорий в Заволжье необходимо провести дополнительные специальные исследования, наметить тактические и стратегические задачи и цели, выявить наиболее значимые объекты. В современной динамично меняющейся социально-экономической ситуации, существенным образом влияющей на состояние степных геосистем, дальнейшие специальные исследования восточной окраины Саратовского Заволжья с последующим резервированием степных участков для создания ООПТ - необходимый элемент сбалансированной региональной экологической политики.

\section{Библиографический список}

1. Макаров В.3. Карта. Ландшафтное районирование Саратовской области (при участии И.В. Пролеткина и
А.Н. Чумаченко) // Эколого-ресурсный атлас Саратовской области. Саратов, 1996. С. 7.

2. Доклад о состоянии и об охране окружающей среды Саратовской области в 2006 году. Саратов, 2007. 283 с.

3. Мальиева Г.С., Малаховский П.Д. Разнообразие степей Саратовского Заволжья и их современное состояние // Бот. журн. 2004. Т. 89, № 6. С. 973-986.

4. Особо охраняемые природные территории Саратовской области: национальный парк, природные микрозаповедники, памятники природы, дендрарий, ботанический сад, особо охраняемые геологические объекты / Комитет охраны окружающей среды и природопользования Саратовской области. Саратов, 2007. 300 с.

5. Федеральный закон № 33-Ф3 «Об особо охраняемых природных территориях» от 14 марта 1995 года // СПС «КонсультантПлюс».

6. Фондовые материалы лаборатории урбоэкологии и регионального анализа Сарат. гос. ун-та им. Н.Г. Чернышевского, 2007, 2008 гг.

7. Волков Ю.В. Структура и элементы природно-экологического каркаса и ООПТ Саратовской области // Поволжский экологический журн. 2008. № 4. С. 264-274.

8. Постановление правительства Саратовской области №385-П «Об утверждении перечня особо охраняемых природных территорий регионального значения Саратовской области» от 1 ноября 2007 года // СПС «КонсультантПлюс».

9. Еленевский А.Г., Буланый Ю.И., Радыгина В.И. Конспект флоры Саратовской области. Саратов, 2008. 250 с.

10. Красная книга Саратовской области: Грибы. Лишайники. Растения. Животные / Комитет охраны окружающей среды и природопользования Сарат. обл. Саратов, 2006. $528 \mathrm{c}$.

УДК 55:004:622.992.2-032.32:504(470.44)

\title{
МОДЕЛИРОВАНИЕ ФАКТОРОВ ПОЖАРООПАСНОЙ СИТУАЦИИ НА НЕФТЕСБОРНЫХ ПУНКТАХ С ИСПОЛЬЗОВАНИЕМ ГЕОИНФОРМАЦИОННЫХ ТЕХНОЛОГИЙ
}

\section{В.З. Макаров, А.В. Молочко, В.А. Фролов ${ }^{1}$, А.Н. Чумаченко}

Саратовский государственный университет, кафедра физической географии и ландшафтной экологии, ${ }^{1}$ кафедра геоморфологии и геоэкологии

20АО «Саратовнефтегаз»

E-mail: gis@sgu.ru

В статье рассмотрены картографо-математические модели аварийных ситуаций на нефтесборных пунктах и прилегающей территории. На основе ГИС-моделирования созданы прогнозные модели зон аварийного разлива нефти, взрывоопасных концентраций при испарении нефтепродуктов с поверхности разлива, определены радиус зон избыточного давления, опасные для здоровья зоны теплового излучения при пожаре нефтепродукта.

Ключевые слова: геоинформационное моделирование, нефтесборные пункты, пожарная безопасность, техногенные риски.
Fire Situation Modeling within Oil-Gathering Stations Using

\section{Geoinformation Technologies}

\section{V.Z. Makarov, A.V. Molochko, V.A. Frolov,}

\section{A.N. Chumachenko}

This article is represented cartographical-mathematical models of oil-gathering stations' fire risk factors for population and surrounding area. Based on geomodeling are created models of oil outflow, explosive concentration in the time of oil evaporation, models of overpressure risk areas' radius, thermal radiation risk area modeling in time of oil fire.

Key words: geoinformation modeling, oil-gathering stations, fire safety, anthropogenic risks. 


\section{Постановка проблемы}

Одной из причин роста числа чрезвычайных ситуаций в промышленности, многие из которых приводят к тяжелым последствиям, является преимущественное использование технологии наземного хранения токсичных пожаро- и взрывоопасных веществ. Резервуарные парки предприятий часто находятся вблизи селитебных территорий и представляют собой источники потенциальной опасности для населения [1]. Полное или частичное разрушение резервуаров или технологического оборудования приводит к разливу горючих жидкостей, а наличие источников возгорания - к возникновению так называемых «пожаров разлития». «Пожар разлития» отличается весьма сложным характером, зачастую большими масштабами и имеет склонность к распространению на близлежащие территории. Пожары на производственных объектах наносят как большой материальный ущерб, так и ущерб жизни и здоровью людей.

Невозможность отказаться от большинства потенциально опасных технологий и существенно сократить объемы использования горючих жидкостей обусловливает необходимость развития новых подходов к изучению пожароопасных объектов и выработке рекомендаций по обеспечению безопасности как самих объектов хранения таких веществ, так и территорий, прилегающих к ним. Все большее распространение получает подход, основанный на анализе подобных рисков и управлении ими с помощью геоинформационных технологий. Для этого необходимо знать в первую очередь пространственно-временное распределение поражающих факторов (термическое воздействие и воздействие открытого пламени) и факторов (природного, техногенного или социального характера), оказывающих влияние на ситуацию.

\section{Методы и исходный материал}

В данной статье предложен опыт геоинформационного моделирования аварийных ситуаций на примере изучения пункта сбора нефти и газа «Языковка» (НСП) ОАО «Саратовнефтегаз», расположенного в Аткарском районе Саратовской области на расстоянии 1 км к юго-западу от с. Языковка. Основной материал получен при изучении фондов ОАО «Саратовнефтегаз» и данных полевых работ. Картографо-математические модели строились в среде MapInfo 8.5. [2].

Технический регламент о требованиях пожарной безопасности от 22.07.2008 г. № 123-Ф3 предусматривает дислокацию подразделений пожарной охраны на территориях поселений и городских округов, определяющуюся исходя из условия, что время прибытия первого подразделения к месту вызова в городских поселениях и городских округах не должно превышать 10 мин, а в сельских поселениях - 20 мин [2]. Основу противопожарной защиты Аткарского муниципального района образуют 3 пожарных депо. Из них 2 депо расположены в административном центре - г. Аткарск и 1 депо - в с. Озерное [3].

Исходя из технического регламента и методики расчета транспортной доступности, были построены изохроны 20-минутной доступности пожарных депо (рис. 1). Каждому типу дорог в зависимости от статуса (региональная, местная, межмуниципальная) и покрытия (грунтовая проселочная, шоссе, усовершенствованное шоссе) присваивалось уникальное значение средней скорости движения по ним автомобильного транспорта. Затем проводился расчет времени в каждом узле дорожной сети, за которое автомашина может преодолеть определенное расстояние, двигаясь от населенных пунктов, заявленных как места дислокации пожарных депо. Оказалось, что хотя от ближайшего пожарного депо в с. Озерном до НСП «Языковка» всего 21 км, пожарной машине, чтобы добраться до конечного пункта, понадобиться 50 мин. Это значительно превышает установленные стандарты 20-минутной транспортной доступности. В связи с этим возникновение пожара на данном НСП изначально представляет собой серьезную проблему.

На объектах добычи и подготовки нефти и газа, к которым относится объект моделирования, при возникновении инцидентов горение нефти и нефтепродуктов может происходить как непосредственно в резервуарах и технологических аппаратах, так и при их разливе на открытых площадях. Основную опасность во время пожара при любых условиях вызывает лучистая энергия, являющаяся мощным источником зажигания, способным вызывать горение других конструкций, материалов и веществ [4].

При пожаре нефтепродуктов в резервуарах могут происходить взрывы, вскипание горючего вещества с их последующим выбросом. Опыт показывает, что тонны вещества могут быть выброшены на расстояние более восьми диаметров емкости [5]. При этом площадь горения может достигать нескольких тысяч квадратных метров.

Возникновение пожара в резервуаре зависит от следующих факторов: наличия взрывоопасных концентраций внутри и снаружи резервуара, источника возгорания, свойств горючей жидкости.

Пожар в резервуаре в большинстве случаев начинается со взрыва паровоздушной смеси. На образование взрывоопасных концентраций внутри резервуаров оказывают существенное влияние физико-химические свойства хранимых нефти и нефтепродуктов, конструкция резервуара, нарушение технологических режимов эксплуатации резервуара, а также климатические и метеорологические условия. Взрыв в резервуаре приводит к подрыву (реже срыву) крыши с последующим горением по всей поверхности горючей жидкости. При этом даже в начальной стадии горение 


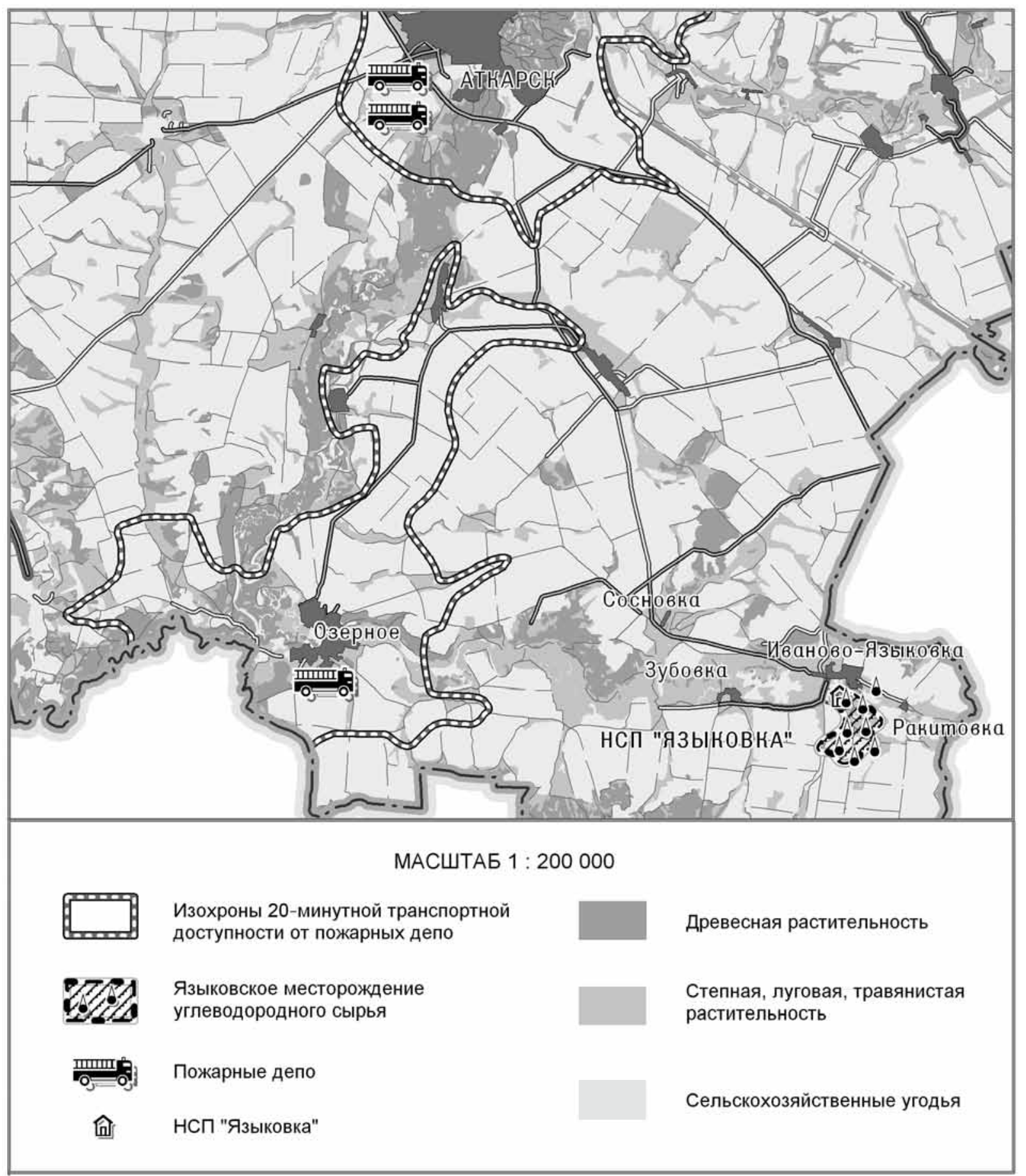

Рис. 1. Удаленность НСП «Языковка» от пожарных депо

нефти и нефтепродуктов в резервуаре может сопровождаться мощным тепловым излучением в окружающую среду, а высота светящейся части пламени составлять 1-2 диаметра горящего резервуара. Отклонение факела пламени от вертикальной оси при скорости ветра около $4 \mathrm{M} / \mathrm{c}$, составляет $60-70^{\circ}$ [5].

Определение показателей пожарной опасности взрывопожароопасных предприятий для населения и территории основано на гипотетиче- ском варианте реализации аварийной ситуации с переходом в пожар, развивающийся по наиболее неблагоприятному варианту на предприятии [6].

В качестве наиболее неблагоприятного варианта рассматривается случай хрупкого (полного) разрушения резервуара, связанного с образованием гидродинамической волны нефтепродукта, которая либо промывает обвалование, либо перехлестывает через него и разливается на значительной площади за территорией объекта. 
Для полноты картины последствий рассматриваются варианты, связанные с полным разрушением как резервуара наибольшей вместимости, так и с резервуаром меньшей вместимости, но наиболее близко расположенным к жилым массивам.

\section{Содержание картографо-математических моделей}

1. Определение зоны аварийного разлива нефтепродукта.

Определение зоны аварийного разлива нефтепродукта предусматривает два варианта расчетов [6]:

- в пределах обвалования, вследствие нарушения технологии заполнения резервуара нефтепродуктом или локального (точечного) повреждения резервуара;

- в случае крупномасштабной аварии, связанной с полным разрушением наземного вертикального стального резервуара.

В нашем случае прогнозировались зоны аварийного разлива при крупномасштабной аварии.

При расположении резервуара в низине или на ровной поверхности зону разлива рассматривают в виде круга. Радиус этой зоны характеризует максимальное расстояние разлива от центра резервуара. При расположении резервуара на возвышенности зону разлива рассматривают в виде эллипса. Форму эллипса характеризуют большая и малая оси. Большую ось отсчитывают от центра резервуара.

Основная часть моделируемого объекта (НСП «Языковка») расположена на территории с уклонами $0-1^{\circ}$, реже $1-3^{\circ}$. Поэтому в качестве формы зоны разлива в данном случае будет принята окружность.

Площадь зоны разлива вычисляется по формуле

$$
F_{\text {зр }}=f_{3} \varepsilon_{\mathrm{p}} V_{\mathrm{p}},
$$

где $F_{3 р}$ - площадь зоны разлива, м ${ }^{2} ; f_{3}$ - коэффициент разлива, ${ }^{-1} ; \varepsilon_{\mathrm{p}}-$ степень заполнения резервуара; $V_{\mathrm{p}}$ - номинальная вместимость резервуара, $\mathrm{m}^{3}$.

Степень заполнения резервуара допускается принимать равной 0,9.

Коэффициент разлива определяют исходя из расположения наземного резервуара на местности:

$$
f_{3}=\left\{\begin{array}{l}
5-\text { при расположении в низине } \\
\text { или на ровной поверхности } \\
\text { с уклоном до } 1 \% \\
12 \text { - при расположении на возвышенности }
\end{array}\right.
$$

Приведенную форму зоны разлива нефтепродукта принимают в зависимости от расположения резервуара на местности. При расположении в низине или на ровной поверхности - в виде круга с радиусом:

$$
R_{\text {зр }}=\sqrt{F_{\text {зр }} / \pi} \text {. }
$$

На территории НСП «Языковка» находятся две емкости объемами $72 \mathrm{~m}^{3}$ и $60 \mathrm{~m}^{3}$. Площадь аварийного разлива для каждой из них будет составлять около $450 \mathrm{M}^{2}$, радиус зон соответственно 12 м. По результатам определений была построена карта прогнозируемых зон разлива, которая представляет собой ситуационный план с нанесением расчетных зон разлива (рис. 2).

2. Определение зоны взрывоопасных концентраций при испарении нефтепродукта с поверхности разлива.

Зоны взрывоопасных концентраций определялись на основании проведенных в России исследований по изучению закономерностей распределения концентраций взрывоопасных газов и паров на открытых территориях в Главной геофизической обсерватории. Расчетная формула, заимствованная из работы В.М. Эльтермана «Охрана воздушной среды на химических и нефтехимических предприятиях», имеет вид [6]:

$$
X_{\text {звк }}=\sqrt{\frac{A J_{n} \tau}{j_{\text {нп }}}},
$$

где $X_{\text {звк }}$ - расстояние от источника испарения, м; $A$ - константа, равная 0,$17 ; J_{\mathrm{n}}$ - интенсивность испарения, кг $\cdot \mathrm{c}^{-1}, t-$ продолжительность испарения, с; $j_{\text {нп }}-$ нижний концентрационный предел распространения пламени для нефтепродуктов равный 0,04 кг $\cdot \mathrm{M}^{-3}$.

При отсутствии номенклатуры резервуаров аварийные зоны взрывоопасных концентраций при испарении нефтепродукта с поверхности разлива определяют для наиболее неблагоприятного варианта метеоусловий, способствующего образованию максимально возможных аварийных зон взрывоопасных концентраций. Подвижность воздуха принимается равной нулю, а температура нефтепродукта - среднемесячной температуре окружающей среды для июля. В итоге аварийной зоной взрывоопасных концентраций при испарении нефтепродукта с поверхности разлива от каждой емкости будет площадь в $450 \mathrm{~m}^{2}$, а глубина взрывоопасной зоны от границы разлива нефтепродукта - 30 м. По результатам определения была составлена карта прогнозируемых зон взрывоопасных концентраций (см. рис. 2).

3. Определение опасных зон теплового излучения при «пожаре разлития» нефтепродукта.

Опасные зоны теплового излучения при «пожарах разлития» определяют для наиболее неблагоприятного варианта [6].

В качестве критерия опасного теплового воздействия на границе зоны приняты:

- для людей - тепловые нагрузки, превышающие 1,4 кВт $\cdot \mathrm{M}^{-2}$;

- сгораемых элементов конструкций зданий (двери, рамы и т.п.), а также резервуаров с нефтепродуктами, не оборудованных установками охлаждения, $-7,5 \mathrm{\kappa BT} \cdot \mathrm{M}^{-2}$;

- резервуаров с нефтепродуктами, оборудованных установками охлаждения, -13 кВт $\cdot \mathrm{M}^{-2}$. 


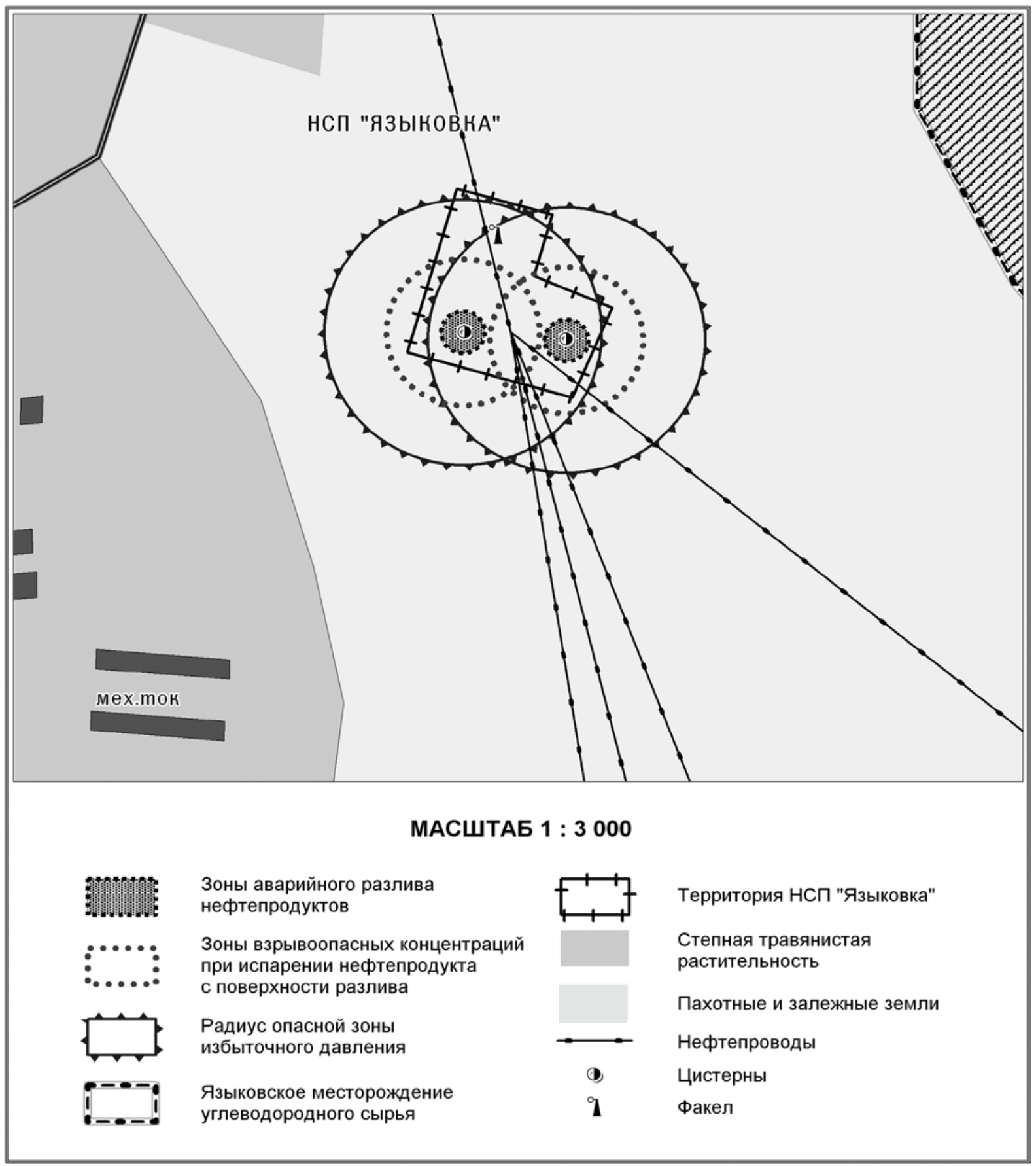

Рис. 2. Зоны аварийного разлива, зоны взрывоопасных концентраций при испарении нефтепродукта с поверхности разлива, радиус опасных зон избыточного давления и обустройство НСП «Языковка»

При расчете опасных тепловых зон плотность теплового излучения «пожара разлития» принята равной $50 \kappa В \mathrm{KT} \cdot \mathrm{M}^{-2}$.

При отсутствии характерных размеров зон разлива нефтепродукта опасность теплового излучения пожара определяют для крупномасштабной аварии по следующим формулам методом последовательных приближений:

1) плотность потока теплового излучения $\left(q_{n}\right)$ на границе зоны при горении нефтепродукта на площади разлива, кВт $\cdot \mathrm{M}^{-2}$ :

$$
q_{n}=q_{\phi}-F_{\text {обл }},
$$

где $q_{\phi}$ - максимальная среднеповерхностная плотность излучения, кВт $\cdot \mathrm{M}^{-2} ; F_{\text {обл }}-$ коэффициент облученности;

2) максимальная среднеповерхностная плотность излучения факела пламени пожара в штиль, кВТ $\cdot \mathrm{M}^{-2}$ :

$$
q_{\phi}=\left(335+7112 / d_{\mathrm{p}}\right) m_{\text {выг }},
$$

где $d_{\mathrm{p}}$ - характерный диаметр зоны разлива, м; 
$m_{\text {выг }}$ - массовая скорость выгорания нефтепродукта, кг $\cdot \mathrm{c}^{-1} \mathrm{M}^{-2}$.

В данном случае опасные зоны теплового излучения при «пожарах разлития» нефтепродуктов для людей, сгораемых элементов конструкций зданий, резервуаров с нефтепродуктами, оборудованных установками охлаждения для каждой емкости, будут равны соответственно 60, 27 и $15 \mathrm{\kappa BT} \cdot \mathrm{M}^{-2}$.

По результатам определения была составлена карта, представляющая собой ситуационный план с нанесенными опасными зонами тепловых излу- чений. При «пожаре разлития» нефтепродукта на площади круга тепловые зоны будут представлять собой окружности, а при горении нефтепродукта на площади эллипса тепловые зоны будут повторять его форму (рис. 3).

Однако не стоит забывать, что данные модели реализованы для крайнего случая, с полным разрушением емкостей с нефтепродуктами. На НСП «Языковка», в рамках обеспечения пожарной безопасности, а также предупреждения возникновения пожаров и локализации их на ранней

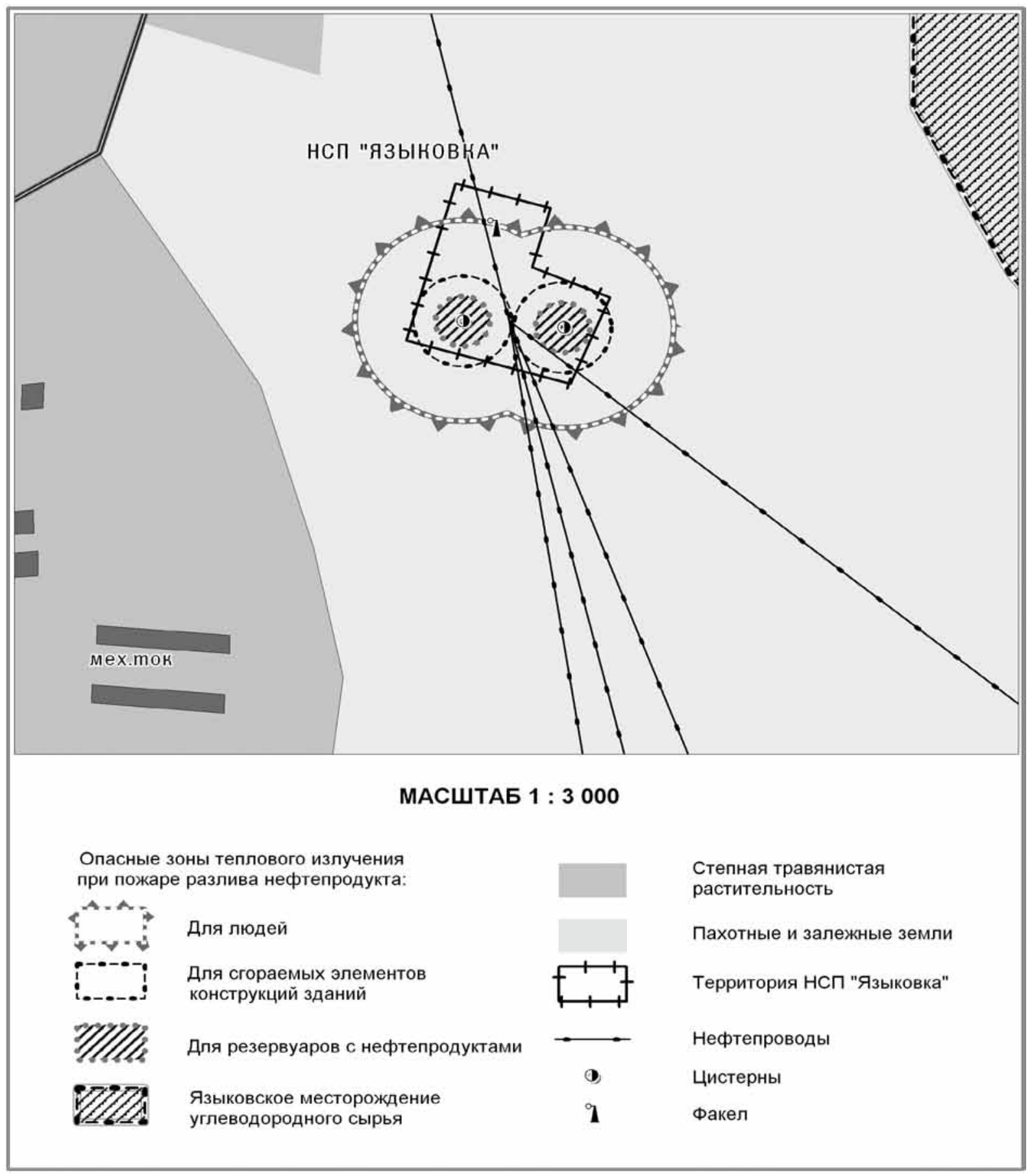

Рис. 3. Опасные зоны теплового излучения при пожаре нефтепродукта на НСП «Языковка» 
стадии, предусмотрены первичные средства пожаротушения, расположенные на территории НСП, на пожарных щитах [2]. Пожарные щиты укомплектованы согласно «Перечню средств пожаротушения» пожарным инвентарем: ведром, лопатой совковой, багром, ломом, топором, ящиком с песком, кошмой. Для тушения пожара предусмотрены также порошковые огнетушители и углекислотные огнетушители.

\section{Выводы}

В кратчайшие сроки провести оценку, локализацию и устранение взрывоопасной ситуации с минимизацией потерь человеческих и материальных ресурсов - вот главные задачи, которые ставятся перед использованием геоинформационного моделирования рисковых ситуаций на объектах нефтяного комплекса. Использование всего спектра возможностей геоинформационных систем (в частности, моделирования, геоанализа, построения буферных зон, расчета транспортной доступности и проч.) существенно ускорит процесс принятия решений и планирования мер, связанных с защитой населения и объектов хозяйственного использования на уровне муниципального района. Особенно важно своевременное принятие решений на основе ГИС-технологий не столько для крупных населенных пунктов, сколько для сельских поселений, не обладающих достаточно широкой материально-технической базой для противопожарной защиты. В частности, при анализе территорий, расположенных в 20 минутах от пожарных депо для Аткарского района, очевидна недостаточная обеспеченность муниципального района пожарными депо, особенно в зоне риска - Языковского нефтегазового месторождения, расположенного в непосредственной близости от сел Языковка, Иваново-Языковка, деревень Ракитовка, Зубовка. Данные моделирования показали, что при самом критическом случае - полного разрушения емкостей с нефтепродуктами и последующим их возгоранием - зона распространения опасного избыточного давления и опасных концентраций выходит за пределы технологической площадки Языковского пункта сбора нефти и газа. Поскольку НСП представляет собой не только место хранения, но и место дальнейшей транспортировки нефтепродуктов, то зона поражения может значительно увеличиться за счет возгорания нефтепровода и скважин попадающих в зону поражения. А это, в свою очередь, усиливается следующими факторами:

- климат Аткарского муниципального района умеренно континентальный, с жарким и сухим летом;

- растительность рассматриваемой местности степная, а также представлена пахотными и залежными землями;

- в летний период преимущественное направление ветров - северное и северо-восточное;

- села Языковка и Иваново-Языковка располагаются всего в 1 км от НСП.

Все это говорит о том, что риск для населения, строений и окружающей среды может возрастать в несколько раз. Именно поэтому применение ГИС для анализа пожарной опасности повысит скорость принятия решений и снизит вероятность ошибок при проведении реальных противопожарных мероприятий в случае аварии, а также поможет более эффективно провести планирование и строительство системы объектов пожарной безопасности района.

\section{Библиографический список}

1. Атнабаев А.Ф., Бахтизин Р.Н., Нагаев Р.З. и др. ГИС-модели для анализа последствий аварийных разливов нефти // Arcreview. 2006. № 3(26). С. 15-16.

2. Макаров В.3., Чумаченко А.Н., Федоров А.В. и др. Применение ГИС-технологий при изучении факторов природного риска на нефтяных месторождениях Нижнего Поволжья // ИнтерКарто-ИнтерГИС 10: устойчивое развитие территорий: геоинформационное обеспечение и практический опыт: Материалы Междунар. конф. Владивосток, Чаньчунь (КНИР), 12-19 июля 2004 г. Владивосток; Чаньчунь, 2004. С. 116-120.

3. Демографический ежегодник Саратовской области, 2006 год: Стат. сб. / Территориальная организация Федеральной службы государственной статистики по Саратовской области. Саратов, 2007. 186 с.

4. Сербии С.М., Колупаев Г.А. Методические указания к изучению темы «Чрезвычайные ситуации, связанные с пожарами и взрывами». М., 1999. 34 с.

5. Безродный И.Ф., Меркулов В.А., Шариков А.В. Руководство по тушению нефти и нефтепродуктов в резервуарах и резервуарных парках. М., 1999. $46 \mathrm{c}$.

6. Сучков В.П., Куликов А.В., Молчанов В.П. и др. Рекомендации по обеспечению пожарной безопасности объектов нефтепродуктообеспечения, расположенных на селитебной территории. М., 1997. 23 с. 